\title{
Specifics of the Organization of Group Learning in Large Student Groups
}

\author{
Yu-min SUN ${ }^{1, *}$ and Elena MIKITCHENKO ${ }^{2}$ \\ ${ }^{1}$ Russian center of University of Sanya, China \\ ${ }^{2}$ University of Sanya, China \\ *Corresponding author
}

\begin{abstract}
Keywords: Intensive, Training Methods, Group Forms of Learning, Large Student Groups, Organizational Difficulties.
\end{abstract}

\begin{abstract}
The paper substantiates the necessity to improve the methods of group learning of foreign languages (in this situation, Russian) in large student teams and outlines the difficulties that instructors of foreign language may face on this way. The authors give recommendations not to be apprehensive of organizational problems and to tend to use the well-known methods of group learning, adjusting them to a particular group's actual learning environment, providing a platform for improvement of each student's learning skills and, therefore, for enhancement of the entire education.
\end{abstract}

\section{Introduction}

The present-day methodology of teaching Russian as a foreign language is being developed under the sign of communicative teaching, underlying the importance of the instructor's skill to involve student's potentialities into the teaching situation, both psychological - personal endowments, and socio-psychological - the abilities attributed to the interaction between the individual and the group.

"Mainstreaming of the class activity can be achieved by various means:

1) diverse forms of organizing learning material, its concentration and distribution, special methods, techniques, various forms of participation, etc.;

2) the method of stepping up the performance potential of the group and the individual, or the 'intensive method', presents another mean of mainstreaming the learning activity” [1].

\section{Intensive Teaching}

The classes of Russian as a foreign language most widely introduce the activization method, the theoretical foundations of which have been studied by G.A. Kitaigorodskaya [2]. From the traditional teaching, intensive differs primarily in the way of organizing and conducting classes, where special attention is paid to various forms of pedagogical communication and the creation of a friendly psychological environment in the group as this helps to lift psychological barriers when mastering linguistic material and to lift up students' academic motivation.

Under the intensive language learning student dips into the atmosphere of a role game where he or she acts as some character in a group of other people studying foreign language and acting definite parts as well. The speech material amounts to polylogues in the language that students must master. Advocates of that method believe that the intensive learning "implies a significant increase in the volume of learning material and strengthening of the joint instructor-student activities, aimed at the acquiring of knowledge, through students' highest possible engagement in the process of managed group influence, communication-training” [3].

Methodological literature marks such underlying principles of the intensity of learning as follows: the activation of class activity (including communicative), collective interaction, personality-oriented communication, responsible language learning, the greater concentration of learned material, the variability of techniques and exercises, the high intension of communication, and the comfortable communicative situation in class [4]. 
There are various interactive methods of teaching foreign languages, benefiting the development of students' foreign language communicative competence. Those include also modeling of dialogues in a role game. Methodologist N. L. Suvorova assumes that the role game offers "learning through communication when group interaction bases on the participants' dynamism, while the emphasis is put on the independent, proactive game activity" [5].

The role game as a tool of students' joint class activity and the way of modeling person-to-person group communication meets all those principles of the intensive learning. At the same time, a small number of participants (10 students at most), the elimination of an excessive officiality, a relaxed environment through communicants' free movement and the choice of their location, a small distance between the seated are among the prerequisites for the naturalness and comfort of communication in such group learning form.

\section{Specifics of the Organization of Group Learning in Large Student Groups}

How can all this be applied practically in the conditions of teaching Russian as a foreign language in China, when the instructor is put in a situation different from that in Russia, where the optimum capacity per group studying foreign language has its limits (6-10 students)? In Chinese universities a group of 30 students studying foreign language is considered to be a small group and standard groups consist of 50-100 students. Thus, the instructor of Russian in his/ her work immediately faces problems, and the domestic methodology has no clear-cut answer to their troubleshooting thus far. The authors have already marked in their previous work that "the methodology of teaching Russian as a foreign language does not offer sufficient research and recommendations for working in large groups" [6].

Another example is the work of O. V. Nefyodov (teaching in Korea) Outlook on writing a textbook for large multilevel groups of students of a nonlinguistic university, writing that it is very complicated to give an exact definition of a large group for universities in Asia, since "the answer to this question may vary from country to country ", and that "instructing a foreign language in large multilevel groups presents significant difficulties" [7].

In the work Some problems of instructing group communication at French lessons and the ways to overcome them G. D. Tkachuk also addresses that problem [8].

Instructors of the Faculty of the Russian Language at University of Sanya , Hainan, make efforts to stem the difficulties with teaching in large groups - they introduce in classes both the traditional, classic methods and more advanced (play forms, dramatics - playing tales and pieces with singing and dancing while preparing for concerts, or at meetings of the Russian Club and in the Russian language classes (T. Yu. Yarovaya), playing scenes of life in a dialogue form during class exercises, using elements of students' cross check and collaborative learning in small groups during extra curriculars on speech development and other (E. S. Mikitchenko).

Actively using in class exercises collective and group (including game) forms of work, the instructors of Russian (including those who came from Russia) keep in mind the individual approach and try to find time for each student.

They are in constant aspiration and search for more effective and efficient forms of work that contribute to better mastering by students of the foreign language, in this case - Russian.

If, for several reasons, it is impossible in large Chinese students' classes to accurately pattern the process of intensive teaching of Russian in its classical form, nevertheless, one can consider the achievements of this system of teaching when working with foreign students. It is especially important to address the basis for the activation method itself, in which the principle of collective interaction becomes the guiding one. This principle combines the goals of learning and personal development into single teaching and educational process.

\section{Consideration of the Organizational Problems with the Arrangement of Group Forms of Work}

Consequently, the modern understanding of the teaching and learning process' activation implies student teamwork in groups and a special form of communication in such kind of classes with the 
instructor. At present time, however, instructors often find it difficult to directly apply that teaching method (and the group forms of teaching at large) under the conditions of instructing Russian in Chinese universities (more broadly, in Asia), for several reasons as follows:

1) As it was already said, the number of students per class studying foreign languages in the PRC differs from that in similar groups in Russia (and the authors think, in Europe as well) and is distinguished by a great number of students. Organizational problems with applying group forms of work in such large groups and the instructor's ability to fully control the learning process raise the instructor's doubts and fears, which leads to the preference for more traditional forms of instruction.

2) Group forms of work require special arrangement of the learning space-the free spatial faceto-face positioning of little student groups in class (ideally 5-6 students per group), for the purpose of communication, requires corresponding furniture and site, which also raises questions on the part of the organizer of such training. In Russia's Centre of International Education under Moscow State University ten students are considered to be the maximum in Russian learning groups, and students sit round the instructor's desk, facing each other in equal positions; in Russia's school practice schoolchildren sit at different distances from the teacher and their desks make a natural barrier between the students and the teacher. The same picture we also see in Chinese student audiencesstudents, sitting away from the board, may not be psychologically willing to be engaged in the learning process, although the fact of a large audience and a large number of desks is neither bad nor good: everything has its merits and demerits, depending on the training objectives and the forms of work. For instance, the availability of convenient desks is downright necessary for written assignments, while for informal socializing in small groups it is preferable to have no barriers between the speaking that form a small circle);

3) The time frame of such work presents a problem as well because of the lack of the instructor's practice in running such classes or for other reasons: the specifics of the group, different levels of linguistic knowledge, the ability to convey the required information to students (explanation of the assignment requirements, of student's role in a teamwork, evaluation criteria and organizational aspects within the object-some methodologists insist on that), students' motivation and preparedness for the group forms of work, including their psychological compatibility in teamwork, allowance for the diversity of those forms, the effect of certain technical aspects, etc. - all this makes it difficult to accurately time the work within each mini-group of the training team, its monitoring and evaluation;

4) The shortcoming of methodological aids and scientific research results, the independent research and development of lesson plan (how to arrange the process so not to let those students who prepared their group assignments quicker or already reported to the instructor idle, but to actively involve them in listening to other mini-groups), and the preparation of required teaching materials for students, which requires the instructor's great creative efforts and more time. All this does not let the instructor deviate from the traditional, empirically tested teaching methods.

\section{Conclusion}

Whereas in some developed nations with high competition a student is all too often interested in individual advance, in Russia and in China the needs of the state for the development of the national economy urge to increase the level of education of all students. The principle of team spirit in our countries means that the success of everyone becomes the success of the other.

The academic activity, therefore, should be organized to the effect that students' active communication with each other should help them to master and expand new knowledge received in the course of the learning process. Teamwork would benefit knowledge and skills of each. All that is possible provided that there is a teamwork among the participants of the learning interaction that would be optimal in the given learning environment and would serve as a means of increasing its effectiveness.

Despite the above problems for the foreign language instructor with the preparing and conducting lessons using group forms of work in large groups, it should be recommended to introduce and improve those forms of work, as they strongly interest students and give good results. Each instructor- 
specialist in Russian philology, working in large groups, may creatively approach this problem, adjust professional competence in group forms of work under the conditions of running classes in a particular student team and share that experience with all colleagues.

\section{References}

[1] Mukhacheva A.M. Intensive teaching of Russia as a foreign language // Young scientist, 2010, No. 6, pp. 215-220. — URL https://moluch.ru/archive/17/1699/ (reference date: 11.04.2018)

[2] Kitaigorodskaya G. A., Methodological principles of intensive teaching of foreign languages. M.: Moscow University Press, 1986, 175 p.

[3] Guseva I.S., Main principles of implementing the intensive teaching of Russian (initial stage) // Traditions and innovations in the professional activities of the teacher of Russian as a foreign language: Academic monograph, M, 2002, p. 281.

[4] Krechko T.M. Communicative environment in class and the role of communicative tasks at the lessons of French as a mean of educational process' intensification // Lingua mobilis, No. 4(30), pp. 118-123.

[5] Suvorova N. L. Role games and the modeling method // Cherepovets Scientific Readings - 2014. Proceedings of the All-Russian scientific and practical conference (Cherepovets, Nov. 11-12, 2014). Cherepovets State University, 2015, p. 247.

[6] Yu-min Sun and Elena S. Mikitchenko. Group Forms of Students' Activities in Classroom of Russian as a Foreign Language // Advanced Education and Management Engineering. 2017 2nd International Conference on Education, Modern Management and Social Science (EMMSS2017). (Dec. 29-30, 2017, Phuket, Thailand), pp. 100-105.

[7] Nefyodov O.V. "Outlook on writing a textbook for large multilevel groups of students of a nonlinguistic university”, Voronezh, VGPU Izvestia, No.1, 2015, pp. 229-232.

[8] Tkachuk G.D. Some problems of instructing group communication at French lessons and the ways to overcome them. // Foreign Languages at School, 2004, No.7, pp. 46-49. 